\title{
Measles: a disease often forgotten but not gone
}

\author{
Alexander KC Leung *, KL Hon, KF Leong, CM Sergi
}

\section{A B S T R A C T}

Measles (rubeola) is a highly contagious vaccinepreventable disease caused by the measles virus-a virus of the Paramyxoviridae family. The illness typically begins with fever, runny nose, cough, and pathognomonic enanthem (Koplik spots) followed by a characteristic erythematous, maculopapular rash. The rash classically begins on the face and becomes more confluent as it spreads cephalocaudally. Laboratory confirmation of measles virus infection can be based on a positive serological test for measles-specific immunoglobulin $M$ antibody, a four-fold or greater increase in measles-specific immunoglobulin $\mathrm{G}$ between acute and convalescent sera, isolation of measles virus in culture, or detection of measles virus ribonucleic acid by reverse transcriptase-polymerase chain reaction. Complications occur in $10 \%$ to $40 \%$ of patients, and treatment is mainly symptomatic. Bacterial superinfections, if present, should be properly treated with antibiotics. To eradicate measles, universal childhood immunisation and vaccination of all susceptible individuals with measles vaccine recommended, with the first and second doses at ages 12 to 15 months and 4 to 6 years, respectively. The World Health Organization recommends that the first and second doses of measles-containing vaccine be given at ages 9 months and 15 to 18 months, respectively, in countries with high rates of measles transmission.

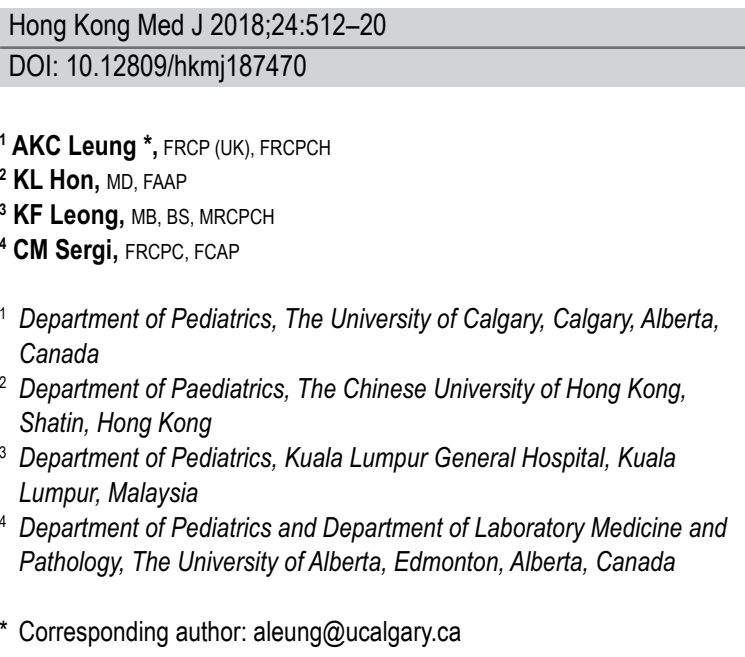

\section{Introduction}

Measles (rubeola) is an extremely contagious, acute febrile viral illness. The illness typically begins with fever, runny nose, cough, and pathognomonic enanthem (Koplik spots) followed by a characteristic erythematous, maculopapular rash. Prior to the introduction of measles vaccine, measles was responsible for more than 2 million deaths worldwide annually. ${ }^{1-3}$ The incidence has declined dramatically over the past 20 years, and measlesassociated mortality had decreased to slightly more than 100000 by 2015 thanks to the increasingly widespread use of attenuated measles vaccines. ${ }^{2}$ Nevertheless, as of today, measles remains an important cause of morbidity and mortality in young children globally, especially in developing countries. ${ }^{4}$ As such, physicians should familiarise themselves with this disease and be able to recognise it early so that isolation measures can be promptly instituted to prevent its spread. This article provides an update on current knowledge about measles and outlines an approach to its evaluation and management.

A PubMed search was conducted in May 2018 using Clinical Queries with the key terms "Measles" and "Rubeola". The search strategy included metaanalyses, randomised controlled trials, clinical trials, observational studies, and reviews. Discussion is based on, but not limited to, the search results.

\section{Aetiology}

The causative organism of measles is the measles virus, a paramyxovirus belonging to the genus Morbillivirus under the family Paramyxoviridae of the order Mononegavirales. ${ }^{2,5}$ The measles virus is spherical, with a diameter ranging from 100 to $200 \mathrm{~nm}$, and shows pleomorphism., ${ }^{5,6}$ The virus contains a single strand of ribonucleic acid (RNA) of negative polarity enclosed within a lipid capsule. ${ }^{5,7}$ The non-segmented genome is approximately 16000 nucleotides in length and contains six genes for eight viral proteins (six structural and two non-structural proteins).,2,78 The six structural proteins are haemagglutinin protein, fusion protein, nucleocapsid protein, phosphoprotein, matrix protein, and large protein. ${ }^{4}$ The haemagglutinin protein binds to cellular receptors and enables the virus to attach to host cells.,4 The fusion protein enables fusion of the viral envelope with the host cell 
plasma membranes, thereby allowing entry of viral ribonucleoproteins into the cytoplasm of the host cell. ${ }^{2,6}$ The phosphoprotein maintains connection with the nucleocapsid protein and large protein to ensure proper viral transcription and replication. ${ }^{5}$ The matrix protein interacts with the ribonucleoprotein complex and the cytoplasmic tails of haemagglutinin protein and fusion protein and thus plays a role in cell fusion. ${ }^{5}$ The two non-structural proteins, $\mathrm{V}$ protein and $\mathrm{C}$ protein, are encoded within the phosphoprotein gene. ${ }^{2,8}$ Although these two nonstructural proteins have no role in maintaining viral structure, they act as virulence factors, facilitating suppression of the host's innate immune response by suppressing interferon production and facilitating virus replication. ${ }^{2,4,5}$

\section{Epidemiology}

Humans are the only known hosts of measles. ${ }^{4,5,9}$ The virus can be transmitted by inhalation of virusladen airborne droplets or small-particle aerosols that remain suspended in the air, direct contact with infected secretions, and less commonly, contact with contaminated fomites. ${ }^{2,9-11}$ Generally, the virus can survive in the air or on fomites for up to 2 hours. ${ }^{1,11}$ As such, disease transmission does not require direct contact with an infected person. ${ }^{7}$ Measles is a highly contagious disease: up to $90 \%$ of susceptible contacts develop the disease. ${ }^{11-13}$

Prior to the introduction of the measles vaccine, more than $90 \%$ of children contracted measles by age 15 years. ${ }^{6,14}$ Since the introduction of the vaccine, the disease has become increasing rare in North America and many developed countries. ${ }^{11}$ Globally, the number of reported cases of measles decreased from 146 cases per million in 2000 to 36 cases per million in 2015. ${ }^{14}$ Most reported cases in 2015 were from Africa. In decreasing order of frequency, the Western Pacific and South-East Asia regions had the next highest frequencies of measles cases. ${ }^{2}$ In the US, the annual incidence of measles was 0.08 and 2.06 per million population in 2001 and 2015 , respectively. ${ }^{15}$ Currently, measles cases in developed countries are primarily "imported" from countries where measles is endemic and occur almost exclusively in unvaccinated or incompletely vaccinated individuals. ${ }^{11,14}$ Outbreaks of measles may occur because of immunity gaps in spite of high overall vaccine coverage. ${ }^{2}$ In developed countries, vaccine negligence or refusal is problematic and accounts for such outbreaks. ${ }^{16-19}$ In March 2018, there was an outbreak of measles in Okinawa, Japan. The measles virus is believed to have entered Japan via travellers in Taiwan.

Genetic characterisation of the measles virus has identified eight classes $(\mathrm{A}-\mathrm{H})$, which can be subdivided into 24 genotypes. ${ }^{20}$ Group A viruses circulate mainly in China, the US, the United

\section{麻疹：一種常被遺忘但未消失的疾病 梁國柱、韓錦倫、梁健寬、CM Sergi}

麻疹是一種高度傳染性的疫苗可預防疾病, 由副黏液病毒屬的麻疹病 毒引起。麻疹通常始於發燒、流鼻涕、咳嗽和黏膜疹（柯氏斑）, 伴 以特徵性紅斑丘疹。丘疹一般從臉部開始, 由上而下曼延然後融合。 經化驗確定的麻疹病毒感染可基於麻疹特異性免疫球蛋白 $\mathbf{M}$ 抗體的陽 性血清學檢測、急性和恢復期血清間麻疹特異性免疫球蛋白G增加4倍 或以上, 以及培養物中麻疹病毒的分離或透過逆轉錄聚合酶鏈式反應 檢測出麻疹病毒核糖核酸。10\%至 $40 \%$ 患者會出現併發症, 大多採用 對症治療。若出現細菌超感染應使用抗生素治療。要根除麻疹, 對所 有易感兒童進行免疫和注射疫苗是理想的做法。已發展國家建議使用 含麻疹疫苗進行常規免疫接種, 為兒童於 12 至 15 個月和 4 至 6 歲時接種 第一和第二劑疫苗。世界衛生組織建議在麻疹傳播率高的國家, 應分 別為兒童於 9 個月和 15 至 18 個月時接種第一劑和第二劑含麻疹疫苗。

Kingdom, Russia, and Argentina. Group B and C viruses circulate mainly in Japan, South Africa, and the Philippines. Group D and E viruses circulate mainly in Western Europe. Group F viruses circulate mainly in Africa. Group G viruses circulate mainly in Canada, Malaysia, and Indonesia. Group $\mathrm{H}$ viruses circulate mainly in China, Japan, and Korea. ${ }^{20}$

Measles affects both sexes equally, ${ }^{14}$ and young children are the most susceptible age-group. ${ }^{4,12}$ Infants born to mothers with vaccine-induced immunity become susceptible to measles at an earlier age than those born to mothers with naturally acquired immunity. ${ }^{2}$ Almost all infants lose their maternal immunity by age 6 months. ${ }^{21}$ However, breastfeeding has a protective effect: breast milk is more likely to contain measles haemagglutination antibodies than blood samples from infants. ${ }^{22}$

Other risk factors include being an infant who is too young to be vaccinated, being an unvaccinated or partially vaccinated individual, travelling to endemic areas, exposure to sick individuals with fever and respiratory symptoms from endemic areas, household exposure, immunodeficiency, malnutrition, and vitamin A deficiency. 7,14

The period of infectivity is maximal in the prodromal phase, before the onset of rash; this coincides with peak levels of measles virus in the respiratory tract and viraemia, which facilitate transmission. ${ }^{12,21}$ Patients are infectious 4 days prior to through 4 days after the onset of the rash. ${ }^{12,21}$

In temperate climates, measles is most common in late winter and early spring. ${ }^{2}$

\section{Pathophysiology}

The inhaled virus from airborne droplets or small-particle aerosols initially infects dendritic cells, lymphocytes, and alveolar macrophages in the susceptible host's respiratory tract.,10 The 
haemagglutinin protein on the viral surface binds to host cell receptors such as human membrane cofactor protein (CD46), signalling lymphocytic activation molecule (CD150), and nectin 4 (PVRL4)..$^{2-6,8,10}$ The fusion protein on the viral surface induces fusion of the viral envelope with the host cell's plasma membranes and fusion between infected host cells and neighbouring cells. ${ }^{8}$ Fusion of the viral envelope with the host cell's plasma membranes facilitates the release of viral ribonucleoproteins into the cytoplasm of the host cell, while fusion between infected host cells and neighbouring cells results in the formation of multinucleated giant cells. ${ }^{2,4,6,8}$ The virus initially replicates locally in the epithelial cells of the upper respiratory tract and then spreads to local lymphatic tissue. ${ }^{2,10}$ Direct cell-to-cell transmission is responsible for dissemination of the virus within the host. ${ }^{8}$

The virus is then disseminated to other reticuloendothelial sites via the blood stream (primary viraemia). ${ }^{7}$ Secondary viraemia occurs several days after primary viraemia, facilitating circulation of the virus to multiple organs such as the skin, lymph nodes, trachea, nose, gastrointestinal tract, liver, kidney, and bladder. ${ }^{2,7,10}$ Virus replication in epithelial cells, endothelial cells, lymphocytes, monocytes, and macrophages may account for the clinical features and complications of measles virus infection. ${ }^{23}$ Infected lymphocytes and dendritic cells transfer the virus to the epithelial cells of the respiratory tract, which are then shed through the damaged epithelium and expelled as respiratory droplets during coughing and sneezing, thereby enabling respiratory transmission to susceptible individuals. ${ }^{2,4}$

Measles virus infection triggers both humoral and cellular immune responses. Cellular immune responses to the virus are vital for viral clearance and recovery, and individuals with $\mathrm{T}$-cell deficiencies often develop severe complications or fatal disease. ${ }^{2}$

During the acute infection and for several weeks to months afterwards, humoral and cellular responses to new antigens are impaired. This can persist for weeks to months, rendering the individual more susceptible to infections caused by other pathogens. ${ }^{5,21}$ Immune amnesia results from replacement of the established memory cell repertoire by measles virus-specific lymphocytes. ${ }^{2}$ Delayed-type hypersensitivity is also decreased.

\section{Histopathology}

The architecture of measles-infected lymph nodes typically shows diffuse follicular, paracortical immunoblastic hyperplasia and diffuse effacement of the lymph node architecture. This pattern may give the appearance of a mottled (moth-eaten) pattern on haematoxylin-eosin staining. Warthin-Finkeldey multinucleated giant cells occur in the prodromal phase of measles in hyperplastic lymphatic tissues. ${ }^{23}$ When antibody titres increase, or at the time of cutaneous eruption, the Warthin-Finkeldey giant cells disappear. Thus, they are observed only sporadically by pathologists in nodal biopsies. Warthin-Finkeldey giant cells are syncytial cells with diameters of 25 to $150 \mu \mathrm{m}$, abundant oeosinophilic cytoplasm, and 4 to 50 hyperchromatic nuclei located at the centre of the syncytia. These cells may also be observed among buccal, conjunctival, or nasopharyngeal cells. ${ }^{23}$

\section{Clinical manifestations}

The incubation period of measles varies from 7 to 21 days, with a median of 13 days. ${ }^{12,18}$ The prodromal phase lasts 2 to 4 days. ${ }^{7,23}$ Prodromal illness caused by measles is characterised by increasing fever, anorexia, malaise, and the classic triad of the three "C"s: coryza (runny nose), cough, and conjunctivitis (red, watery eyes). ${ }^{24}$ Photophobia, peri-orbital oedema, and myalgias may also be present and suggestive of influenza virus infection. One to two days prior to the onset of the exanthem, 1- to 3-mm bluish-white papules with the appearance of "grains of sand or rice" on an erythematous base, which are called Koplik spots, appear on the buccal mucosa opposite the molars; these are pathognomonic for measles infection (Fig 1). ${ }^{23}$ However, Koplik spots are present in only $60 \%$ to $70 \%$ of patients and usually last 12 to 72 hours. ${ }^{7,21}$

Typically, morbilliform exanthem appears 3 to 4 days after the onset of fever and peaks with the appearance of exanthem, ${ }^{11}$ which consists of blanching, erythema, macules, and papules that classically begin on the face, around the hairline, on the sides of neck, and behind the ears. ${ }^{11,25}$ The rash becomes more confluent as it spreads downwards to the trunk and extremities (Figs 2 to 4). ${ }^{1,9}$ The lesions

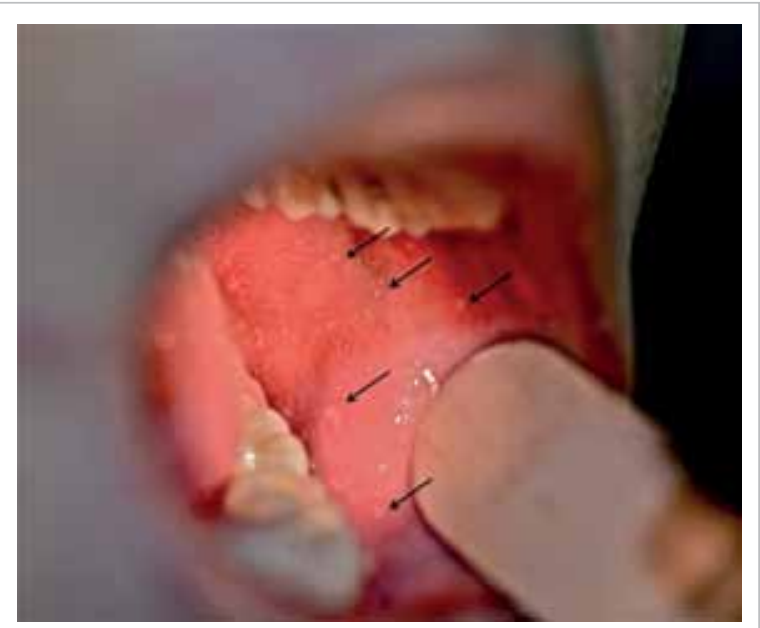

FIG I. Koplik spots (arrows) presenting as bluish-white papules on the buccal mucosa opposite the molars 
are more tense around the shoulders. ${ }^{7}$ The palms of the hands and soles of the feet are rarely affected. ${ }^{26}$ The lesions may be petechial or ecchymotic. ${ }^{7}$ The rash lasts for 5 to 10 days and fades in the same directional pattern in which it appears. ${ }^{7}$ Brownish discolouration (especially in patients of Caucasian descent; Fig 5) with fine desquamation (especially in malnourished patients; Fig 6) sometimes occurs as the rash fades., ${ }^{2,3}$ Fever usually subsides as the rash fades. ${ }^{12}$ Persistence of fever usually indicates complications.

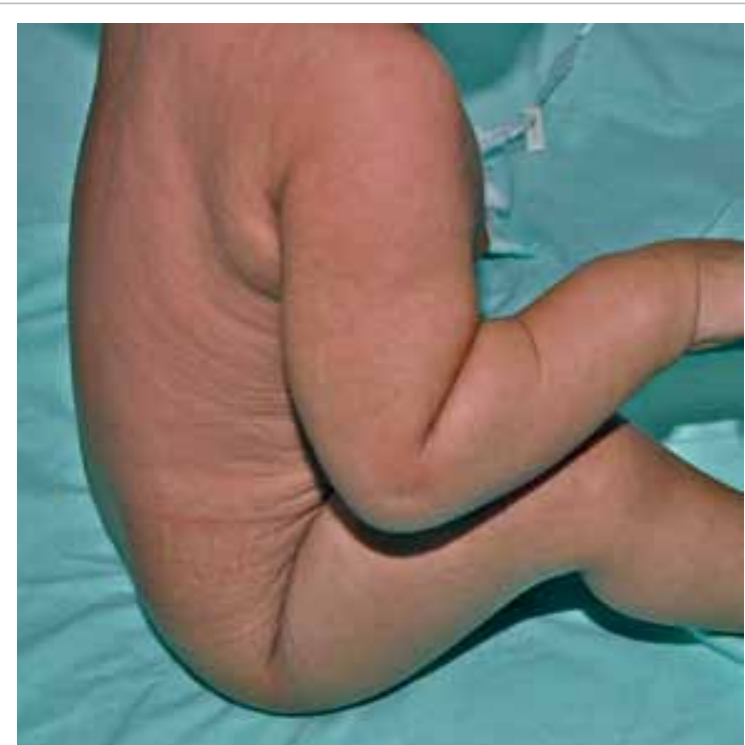

FIG 2. Generalised, erythematous, blotchy rash on an 8-month boy with measles. The rash started on the face and became more confluent as it spread cephalocaudally to the trunk and extremities

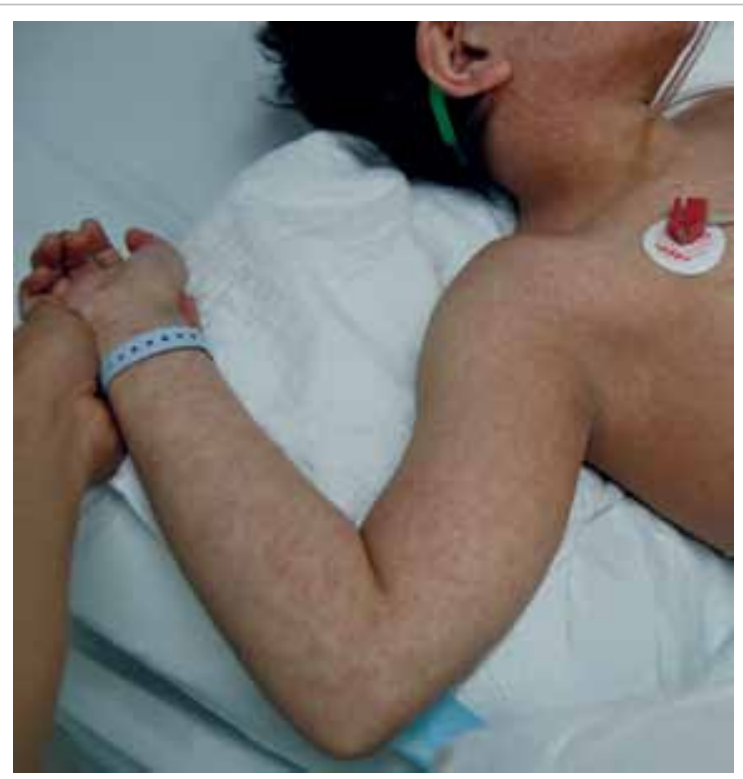

FIG 3. Maculopapular measles rash spreading from the face to the trunk and extremities

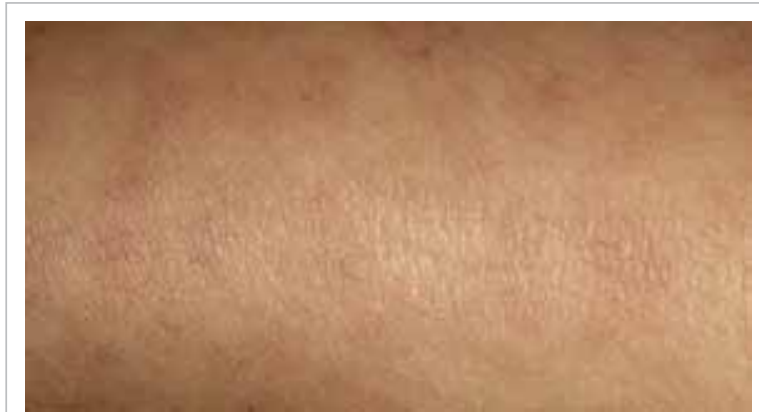

FIG 4. Close-up view of the coalescing maculopapular rash of measles

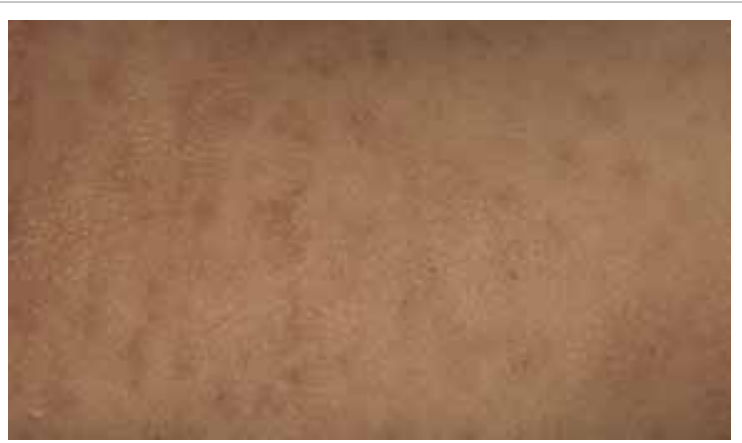

FIG 5. Hyperpigmented lesions seen in areas of pre-existing maculopapular rash

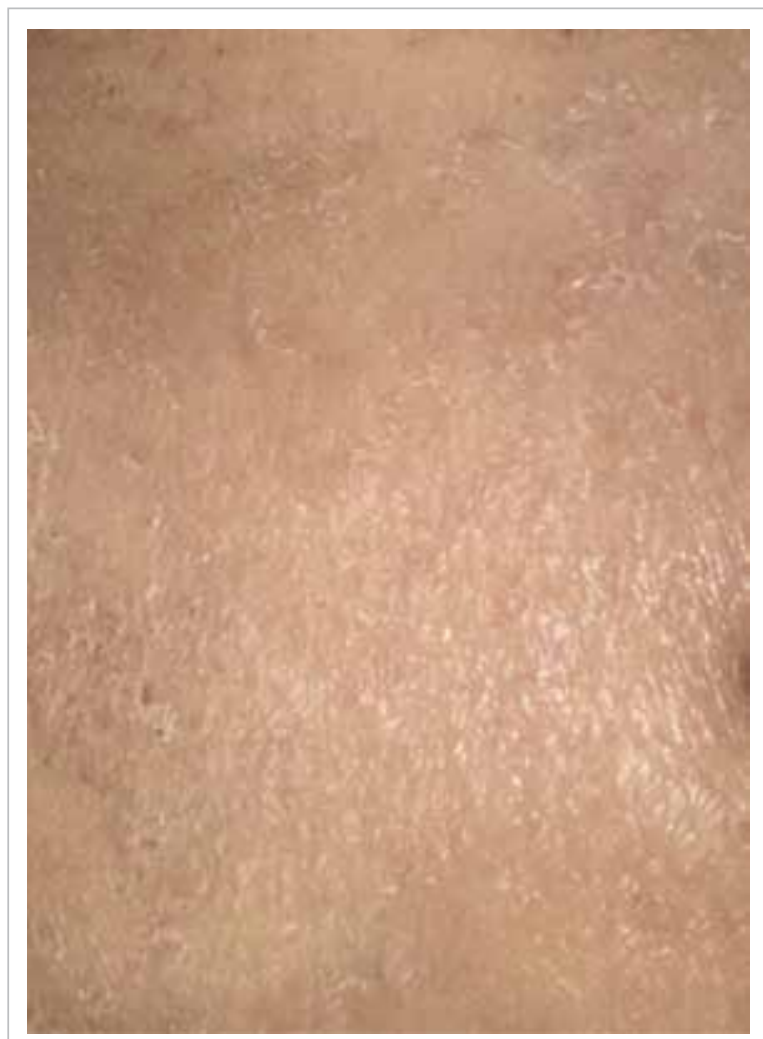

FIG 6. Desquamation seen as the rash fades 
Coughing is consistently present and may persist for weeks. ${ }^{7}$ Sore throat, abdominal pain, cervical lymphadenopathy, and (less commonly) splenomegaly may also be present. ${ }^{23}$

Modified measles occurs in those with preexisting but incompletely protective immunity to measles from either vaccination, previous exposure to the measles virus, transplacental transfer of anti-measles antibody, or receipt of intravenous immunoglobulin. ${ }^{2,23}$ Patients with modified measles have a longer incubation period, milder and less characteristic clinical manifestations, and faster resolution. ${ }^{23,27}$ These patients might not have coryza, cough, or conjunctivitis, and they are less contagious. $^{23,27}$

Atypical measles occurs in individuals who were vaccinated with the killed-virus measles vaccine and who are subsequently exposed to wild-type measles virus. ${ }^{23}$ The killed-virus measles vaccine was used in the US between 1963 and 1967. ${ }^{23}$ The vaccine sensitised individuals to measles virus antigens without providing full protection. ${ }^{23}$ Patients with atypical measles present with headache and high, prolonged fever. ${ }^{23}$ Typically, a maculopapular rash begins on the distal extremities (including the palms of the hands and soles of the feet) and spreads centripetally to the trunk. ${ }^{23}$ The rash may be vesicular, petechial, purpuric, or urticarial. ${ }^{23}$ Severe pneumonia can also occur. Bilateral pulmonary nodules and hilar lymphadenopathy are characteristic. ${ }^{23}$ Some patients may have oedema of the hands and feet, paraesthesia/hyperesthesia, and hepatosplenomegaly.1,12,22 Atypical measles is noncontagious. ${ }^{12}$

\section{Complications}

Complications occur in approximately $10 \%$ to $40 \%$ of patients and are more common and severe in very young, very old, pregnant, immunocompromised, and malnourished patients. ${ }^{1,11,12,21}$ Pneumonia accounts for $60 \%$ of measles-associated death. ${ }^{6}$ Pneumonia can be caused by the measles virus itself (Hecht giant cell pneumonia), or it may be caused by a secondary viral (eg, adenovirus, herpes simplex virus) or bacterial (eg, Streptococcus pneumoniae, Staphylococcus aureus) pathogen. ${ }^{4}$ Other respiratory tract complications include otitis media, sensorineural hearing loss, otosclerosis, tonsillitis, sinusitis, laryngotracheobronchitis ("measles croup"), bronchitis, and exacerbation of tuberculosis. ${ }^{12,28,29}$ Gastrointestinal complications include gastroenteritis, gingivostomatitis, pericoronitis, mesenteric lymphadenitis, hepatitis, pancreatitis, and appendicitis. ${ }^{23,28,30}$ Ophthalmological complications include keratoconjunctivitis, corneal ulceration, and blindness. ${ }^{18}$ Haematological complications include thrombocytopenia and disseminated intravascular coagulopathy. ${ }^{23}$ Cardiac complications include pericarditis and carditis. ${ }^{23}$ Renal complications include glomerulonephritis and acute renal failure. ${ }^{12}$

Neurological complications include febrile seizures, primary measles encephalitis, acute postinfectious encephalomyelitis, measles inclusion body encephalitis, and subacute sclerosing panencephalitis. ${ }^{12,31-33}$ Approximately one in 1000 patients with measles develop primary measles encephalitis, typically on day 5 of the rash (range: 1-14 days). That condition is fatal in approximately $10 \%$ of cases. Acute post-infectious encephalomyelitis is an autoimmune demyelinating disease that occurs approximately one in 1000 patients with measles. The condition typically manifests during the recovery phase, within 2 weeks of the rash. Measles inclusion body encephalitis occurs mainly in patients with impaired cellular immunity within months of the measles infection. That condition may cause progressive brain damage and has a high mortality rate. Subacute sclerosing panencephalitis is a fatal, progressive degenerative central nervous system disease that usually presents 5 to 10 years after the measles virus infection.

Measles in pregnancy is associated with an increased risk of spontaneous abortion, premature labour, low birth weight, intrauterine foetal death, stillbirth, serious measles infection in the neonate, and maternal death., ${ }^{4,11,21}$

Other problems can include absence from school by infected children and loss of income for parents who stay at home to care for them. Thus, the disease has an adverse effect on quality of life. ${ }^{2}$

\section{Diagnosis and differential diagnosis}

Measles should be suspected in the presence of all the following: fever $\geq 101^{\circ} \mathrm{F}\left(38.3^{\circ} \mathrm{C}\right)$; erythematous maculopapular (non-vesicular) rash spreading cephalocaudally from the face downwards and lasting 3 or more days; and at least one of the three "C"s: coryza, cough, or conjunctivitis. ${ }^{11}$ Suspicion should be particularly strong in individuals with no measles immunity if there is a history of exposure to measles, travel to endemic areas (eg, Africa, Western Pacific, and South-East Asia regions), or during an outbreak of measles. Koplik spots, if present, are pathognomonic. Diagnosis can be difficult in areas with low measles incidence.

Differential diagnosis includes rubella, roseola, varicella, erythema infectiosum, handfoot-mouth disease, drug eruptions, scarlet fever, toxic shock syndrome, infectious mononucleosis, Rocky Mountain spotted fever, meningococcaemia, Henoch-Schönlein purpura, systemic lupus erythematosus, Kawasaki disease, and serum sickness. 
Laboratory confirmation of measles virus infection can be based on a positive serological test for measles-specific immunoglobulin M (IgM) antibody; a four-fold or greater increase in measlesspecific IgG titres between acute and convalescent sera; isolation of measles virus from cultures of blood mononuclear cells, urine, conjunctival swabs, or nasopharyngeal secretions; or detection of measles virus RNA by reverse transcriptase-polymerase chain reaction (RT-PCR) from blood, throat, nasal, nasopharyngeal, or urine samples. ${ }^{12,13,23,24}$ Serological testing for measles-specific IgM antibody is the most commonly used method for confirmation of measles virus infection. ${ }^{2}$ Unfortunately, measles-specific IgM antibody might not be detectable until 4 or more days after the onset of rash, which may result in false negative results if the test is conducted early. ${ }^{2}$ Only approximately $75 \%$ of affected individuals will have detectable measles-specific IgM antibody within the first 72 hours after rash onset, but almost all affected individuals will have detectable measles-specific IgM antibody 96 hours after rash onset. ${ }^{2}$ In addition, false positive results may rarely occur in patients with infectious mononucleosis, rubella, parvovirus B19 infection, and rheumatological diseases. ${ }^{12}$ Measles virus RNA testing by RT-PCR, if available, may be preferred to serological testing, as the test is more specific, becomes positive before measles-specific IgM antibody is detectable, and allows genotype identification. ${ }^{1,2,21}$

\section{Management}

Treatment is mainly symptomatic and consists of the use of antipyretics, prevention and control of dehydration, adequate nutrition, and infection control measures. ${ }^{6}$ Bacterial infections, if present, should be properly treated with appropriate antibiotics. ${ }^{6}$ A 2017 Cochrane systematic review showed that vitamin A supplementation is associated with a significant reduction in mortality and morbidity in children with measles. ${ }^{34}$ It is recommended that vitamin A be administered to all children with acute measles orally once daily for 2 consecutive days at age-specific doses (50000 IU, $100000 \mathrm{IU}$, and $200000 \mathrm{IU}$ to infants $<6$ months, infants aged 6 to 11 months, and children $>12$ months, respectively). ${ }^{11,23}$ For children with clinical evidence of vitamin A deficiency, a third age-specific dose is recommended 2 to 4 weeks later. ${ }^{11,23}$

There is no specific antiviral therapy for patients with measles. Although in vitro studies have shown that the measles virus is susceptible to ribavirin, and preliminary studies have shown the efficacy of ribavirin in treatment of patients with measles, ${ }^{35,36}$ no randomised controlled studies have assessed its clinical efficacy and safety profile. Hopefully, well-designed, large-scale, randomised, double-blind, placebo-controlled trials will provide more information on the efficacy and safety profile of ribavirin in children with measles in the future. Until such information is available, ribavirin cannot be routinely recommended.

\section{Prevention}

\section{Active immunisation}

To eliminate measles, population vaccination rates must be over 93\%., ${ }^{4,7}$ Universal childhood immunisation and vaccination of all susceptible patients with measles vaccine is recommended. ${ }^{37}$ Measles vaccines in current use contain live attenuated measles strains that replicate within the host to induce both humoral and cellular immunity. ${ }^{2,25}$ A single dose of measles vaccine given at or after age 1 year is $93 \%$ to $95 \%$ effective at protecting against measles, whereas two doses given at appropriate intervals are nearly $100 \%$ effective. ${ }^{7,11,21}$ However, measles vaccine given at age 9 months is only $85 \%$ protective. ${ }^{21}$

Measles vaccines can be given as a single component (eg, in Russia and some African countries), but they are more often given as combination vaccines, such as measles-mumpsrubella (MMR) and measles-mumps-rubellavaricella vaccines. ${ }^{21}$ The measles-mumps-rubellavaricella vaccine has similar immunogenicity and safety profiles to those of the MMR vaccine, except that there is a two-fold increase in the relative risk of febrile seizures. ${ }^{21}$

In developed countries like the US and Canada, routine immunisation with MMR vaccine is recommended, with the first and second doses given at ages 12 to 15 months and 4 to 6 years, respectively. ${ }^{38,39}$ Measles-containing vaccine is not routinely given before age 12 months because of the less desirable immune response before that age.,11 The World Health Organization recommends that the first and second doses of measles-containing vaccine be given at 9 months and 15 to 18 months, respectively, in countries with high rates of measles transmission. ${ }^{37}$

Measles-containing vaccine should be offered to susceptible individuals (including children aged 6-11 months) who are at higher risk of contracting measles: travellers to endemic areas, high school and college students, health care personnel, and those in the presence of a measles outbreak. ${ }^{12}$ Children who receive one dose of measles-containing vaccine prior to age 12 months should receive two additional doses, separated at least by 28 days, after age 12 months, as doses given before age 12 months should not count as valid doses. ${ }^{21,38}$

Measles vaccines are generally safe and well tolerated. Adverse effects usually occur 5 to 12 days post-vaccination and consist mainly of fever, rash, and arthralgia. ${ }^{11,25}$ There is a possible 
association between measles vaccine and acute disseminated encephalomyelitis, but the excess risk is not likely to be more than 1.16 cases of acute disseminated encephalomyelitis per million vaccines administered. ${ }^{40}$ The accusation that MMR vaccine may lead to autism spectrum disorders is baseless. In 1998 , Wakefield et $\mathrm{a}^{41}$ reported 12 children with ileallymphoid-nodular hyperplasia, non-specific colitis, and pervasive developmental disorder. The authors hypothesised that MMR vaccine could trigger bowel dysfunction leading to gastrointestinal absorption of neurotoxic peptides, with resulting damage to the central nervous system and autism spectrum disorders. The article was found to be fraudulent and was retracted 12 years later. The speculative paper contained a hypothesis that was found by ethical and misconduct committees to have been investigated fraudulently because data were missing. Moreover, the hypothesis was not properly investigated, raising concerns about the quality of the peer reviewers. Unfortunately, the later retracted article was available online for almost 12 years and promoted parental concerns about the safety of MMR vaccine, leading to lower vaccination levels and outbreaks of measles infection in several countries. An evidencebased meta-analysis of five cohort studies ( $n=1256$ $407)$ and five case-control studies $(n=9920)$ found no evidence for a link between MMR vaccination and the subsequent development of autism or autistic spectrum disorders. ${ }^{42}$

Contra-indications for measles vaccination include hypersensitivity to any component of the vaccine, including gelatine and neomycin; confirmed history of an anaphylactic reaction to a previous measles-containing vaccine; cellular immune deficiency; moderate or severe illness; any febrile illness; and pregnancy. ${ }^{7,9,11,25}$ Measles vaccination should be deferred in individuals who have recently used high-dose corticosteroids, immunoglobulin, or blood products. ${ }^{9}$ Almost all states in the US require children to have two doses of measles-containing vaccine to enrol in public school kindergartens. Despite this requirement, the Centers for Disease Control and Prevention (CDC) state-level analysis of kindergarten MMR vaccination rates for the 2014 to 2015 school year found that the median state-level coverage was $94 \%{ }^{43}$

\section{Postexposure prophylaxis}

Measles vaccination given to susceptible contacts within 72 hours of exposure is effective at preventing illness or modifying illness severity and is preferred to immunoglobulin. ${ }^{1,9,37}$ With the exception of pregnant women and immunocompromised individuals, measles-containing vaccine should be given to individuals who cannot provide evidence of immunity to measles as postexposure prophylaxis. ${ }^{26}$

Passive immunisation with immunoglobulin administered intramuscularly or intravenously within 6 days of exposure can also be used to prevent or modify the clinical course of measles. ${ }^{1,33}$ A Cochrane systematic review of seven studies $(n=1432)$ showed that passive immunisation with immunoglobulin is effective at preventing mortality from measles, reducing the risk by $76 \%$ compared with no treatment. ${ }^{44}$ Susceptible people for whom prophylaxis with immunoglobulin is indicated following significant exposure to measles include pregnant women, household contacts aged $<12$ months, and immunocompromised individuals. ${ }^{6,33}$ The recommended dose of immunoglobulin administered intramuscularly is 0.25 to $0.5 \mathrm{~mL} / \mathrm{kg}$ of body weight (maximum $15 \mathrm{~mL}$ ), and the recommended dose administered intravenously is $400 \mathrm{mg} / \mathrm{kg}$ of body weight..$^{9,12,37}$ Individuals weighing $>30 \mathrm{~kg}$ should receive intravenously administered immunoglobulin to achieve protective antibody levels. ${ }^{12}$ Measles vaccination should not be given within 6 months of immunoglobulin administration. ${ }^{12}$

\section{Infection control}

Suspected measles cases should be reported to local public health authorities, and patients with suspected measles should be seen in well-ventilated or negative pressure rooms isolated from other patients. Health care providers and patients should wear appropriate masks (eg, N95) or respirators. ${ }^{1}$ Only health care providers with immunity to measles should be involved in the care of such patients. Confirmed cases of uncomplicated measles can usually be managed at home. ${ }^{12}$ Proper hand washing technique should be emphasised. ${ }^{6}$ Patients with measles should remain in strict airborne isolation and should be excluded from school or work for at least 4 to 7 days after the onset of rash. ${ }^{1,6,23}$ Sick patients such as those with respiratory distress, dehydration, and immunodeficiency should be managed in hospitals with strict airborne transmission precautions for at least 4 days after the onset of rash in otherwise healthy patients or for the duration of illness in immunocompromised patients. ${ }^{12,23}$ Health care personnel should wear appropriate masks or respirators when entering the patient's room and adhere to strict hand washing technique lasting several minutes. Depending on the number of air changes per hour, the patient's room should not be used for up to 207 minutes after the patient's departure. ${ }^{45}$ This is the time required for $99.9 \%$ efficient airborne contaminant removal with 2 air changes per hour. The times required for $99 \%$ and $99.9 \%$ efficient airborne contaminant removal with other numbers of air changes per hour can be found in the "Airborne contamination removal" table (Appendix B, Table B.1). ${ }^{45}$ Individuals susceptible to measles should be excluded from school or work from the 5 th through 21 st day after last exposure; the duration should be extended to 28 
days if prophylactic immunoglobulin is given. ${ }^{46} \mathrm{Such}$ individuals should report promptly to local public health authorities, and their care should adhere to the same airborne transmission precautions as that of suspected cases, should they develop any symptoms or signs of measles during that period. ${ }^{12}$

\section{Prognosis}

The case fatality ratio ranges from less than $0.1 \%$ to $5 \%$, depending on the age of measles acquisition, nutritional status, vaccine coverage, underlying conditions (eg, immunodeficiency, chronic illness), and access to health care ${ }^{8,47}$ Death is usually caused by pneumonia and diarrhoea in developing countries. ${ }^{47}$ Immunity following measles virus infection is life long and is caused by neutralising IgG antibodies to the haemagglutinin protein and creation of memory cells. ${ }^{2,21}$ Second primary attacks are extremely rare. ${ }^{23}$

\section{Conclusions}

Measles is highly contagious and can lead to serious and potentially fatal consequences among individuals who have not been vaccinated. To eliminate measles from a population, universal childhood immunisation and vaccination of all susceptible individuals with measles vaccine is recommended. Generally, vaccination against measles is effective and safe. Outbreaks of measles may occur because of immunity gaps despite high overall vaccine coverage. In developed countries, vaccine refusal is problematic and accounts for such outbreaks.

\section{Author contributions}

All authors have made substantial contributions to the concept or design of this study; acquisition of data; analysis or interpretation of data; drafting of the article; and critical revision for important intellectual content.

\section{Declaration}

As an editor of the journal, KL Hon was not involved in the peer review of the article. All authors have disclosed no conflicts of interest. All authors had full access to the data, contributed to the study, approved the final version for publication, and take responsibility for its accuracy and integrity.

\section{References}

1. Kumar D, Sabella C. Measles: back again. Cleve Clin J Med 2016;83:340-4.

2. Moss WJ. Measles. Lancet 2017;390:2490-502.

3. Strebel PM, Cochi SL, Hoekstra E, et al. A world without measles. J Infect Dis 2011;204(Suppl 1):S1-3.

4. Kondamudi NP, Whitten RA. Measles. Available from: https://www.ncbi.nlm.nih.gov/books/NBK448068/. Accessed 15 May 2018.

5. Bhattacharjee S, Yadava PK. Measles virus: background and oncolytic virotherapy. Biochem Biophys Rep 2018;13:58-62.

6. Dardis MR. A review of measles. J Sch Nurs 2012;28:9-12.

7. Bentley J, Rouse J, Pinfield J. Measles: pathology, management and public health issues. Nurs Stand 2014;28:51-8.

8. Rota PA, Moss WJ, Takeda M, de Swart RL, Thompson KM, Goodson JL. Measles. Nat Rev Dis Primers 2016;2:16049.

9. Caldararo S. Measles. Pediatr Rev 2007;28:352-4.

10. de Vries RD, Mesman AW, Geijtenbeek TB, Duprex WP, de Swart RL. The pathogenesis of measles. Curr Opin Virol 2012;2:248-55.

11. Lindberg C, Lanzi M, Lindberg K. Measles: still a significant health threat. MCN Am J Matern Child Nurs 2015;40:298305.

12. Kobaidze K, Wallace G. Forgotten but not gone: update on measles infection for hospitalists. J Hosp Med 2017;12:4726.

13. MacFadden DR, Gold WL. Measles. CMAJ 2014;186:450.

14. Gans H, Maldonado YA. Measles: epidemiology and transmission. Available from: https://www.uptodate. com/contents/measles-epidemiology-and-transmission. Accessed 25 May 2018.

15. Clemmons NS, Wallace GS, Patel M, Gastañaduy PA. Incidence of measles in the United States, 2001-2015. JAMA 2017;318:1279-81.

16. Zipprich J, Winter K, Hacker J, et al. Measles outbreakCalifornia, December 2014-February 2015. MMWR Morb Mortal Wkly Rep 2015;64:153-4.

17. Hall V, Banerjee E, Kenyon C, et al. Measles outbreakMinnesota April-May 2017. MMWR Morb Mortal Wkly Rep 2017;66:713-7.

18. Piccirilli G, Lazzarotto T, Chiereghin A, Serra L, Gabrielli L, Lanari M. Spotlight on measles in Italy: why outbreaks of a vaccine-preventable infection continue in the 21st century. Expert Rev Anti Infect Ther 2015;13:355-62.

19. Sá Machado R, Perez Duque M, Almeida S, et al. Measles outbreak in a tertiary level hospital, Porto, Portugal, 2018: challenges in the post-elimination era. Euro Surveill 2018;23.

20. Li S, Qian X, Yuan Z, et al. Molecular epidemiology of measles virus infection in Shanghai in 2000-2012: the first appearance of genotype D8. Braz J Infect Dis 2014;18:58190.

21. Bester JC. Measles and measles vaccination: a review. JAMA Pediatr 2016;170:1209-15.

22. Adu FD, Adeniji JA. Measles antibodies in the breast milk of nursing mothers. Afr J Med Med Sci 1995;24:385-8.

23. Gans H, Maldonado YA. Measles: clinical manifestations, diagnosis, treatment, and prevention. Available from: https://www.uptodate.com/contents/measles-clinicalmanifestations-diagnosis-treatment-and-prevention. Accessed 25 May 2018.

24. Campos-Outcalt D. Measles: why it's still a threat. J Fam Pract 2017;66:446-9.

25. Sood SB, Suthar K, Martin K, Mather K. Vaccine-associated measles in an immunocompetent child. Clin Case Rep 2017;5:1765-7.

26. Gadler T, Martinez N, Ogg-Gress J. Recognizing measles, mumps, and rubella in the emergency department. Adv Emerg Nurs J 2018;40:110-8.

27. Roose J, Rohaert C, Jadoul A, Fölster-Holst R, van Gysel D. Modified measles: a diagnostic challenge. Acta Derm Venereol 2018;98:289-90.

28. Bhatt JM, Huoh KC. Otolaryngological manifestations of measles (rubeola): a case report and brief review. Laryngoscope 2016;126:1481-3. 
29. Lai WS, Lin YY, Wang CH, Chen HC. Measles: a missed cause of acute tonsillitis. Ear Nose Throat J 2017;96:E54-5.

30. Nobili V, Pietro S, Stefania P. Fulminant hepatic failure following measles. Pediatr Infect Dis J 2007;26:766-7.

31. Colombo I, Forapani E, Spreafico C, Capraro C, Santilli I. Acute myelitis as presentation of a reemerging disease: measles. Neurol Sci 2018;39:1617-9.

32. Fisher DL, Defres S, Solomon T. Measles-induced encephalitis. QJM 2015;108:177-82.

33. Garg RK, Malhotra HS, Rizvi I, Kumar N, Jain A. An unusual case of acute encephalitic syndrome: is it acute measles encephalitis or subacute sclerosing panencephalitis? Neurol India 2017;65:1333-4.

34. Imdad A, Mayo-Wilson E, Herzer K, Bhutta ZA. Vitamin A supplementation for preventing morbidity and mortality in children from six months to five years of age. Cochrane Database Syst Rev 2017;(3):CD008524.

35. Bichon A, Aubry C, Benarous L, et al. Case report: ribavirin and vitamin $\mathrm{A}$ in a severe case of measles. Medicine (Baltimore) 2017;96:e9154.

36. Ortac Ersoy E, Tanriover MD, Ocal S, Ozisik L, Inkaya C, Topeli A. Severe measles pneumonia in adults with respiratory failure: role of ribavirin and high-dose vitamin A. Clin Respir J 2016;10:673-5.

37. World Health Organization. Measles vaccines: WHO position paper, April 2017-recommendations. Vaccine 2017;pii:S0264-410X(17)30974-X.

38. Drutz JE. Measles, mumps, and rubella immunization in infants, children, and adolescents. Available from: https://www.uptodate.com/contents/measles-mumpsand-rubella-immunization-in-infants-children-andadolescents. Accessed 25 May 2018.

39. McLean HQ, Fiebelkorn AP, Temte JL, Wallace GS; Centers for Disease Control and Prevention. Prevention of measles, rubella, congenital rubella syndrome, and mumps, 2013: summary recommendations of the Advisory Committee on Immunization Practices (ACIP). MMWR Recomm Rep 2013;62:1-34.

40. Baxter R, Lewis E, Goddard K, et al. Acute demyelinating events following vaccines: a case-centered analysis. Clin Infect Dis 2016;63:1456-62.

41. Wakefield AJ, Murch SH, Anthony A, et al. Ileal-lymphoidnodular hyperplasia, non-specific colitis, and pervasive developmental disorder in children. Lancet 1998;351:63741. Erratum in: Lancet 2004;363:750. Retraction in: Lancet 2010;375:445.

42. Taylor LE, Swerdfeger AL, Eslick GD. Vaccines are not associated with autism: an evidence-based meta-analysis of case-control and cohort studies. Vaccine 2014;32:36239.

43. Seither R, Calhoun K, Knighton CL, et al. Vaccination coverage among children in kindergarten-United States, 2014-15 school year. MMWR Morb Mortal Wkly Rep 2015;64:897-904.

44. Young MK, Nimmo GR, Cripps AW, Jones MA. Postexposure passive immunisation for preventing measles. Cochrane Database Syst Rev 2014;(4):CD010056.

45. US Centers for Disease Control and Prevention. Guidelines for environmental infection control in health-care facilities. Available from: https://www.cdc.gov/infectioncontrol/ pdf/guidelines/environmental-guidelines.pdf. Accessed 20 Jul 2018.

46. US New Jersey Department of Health. Vaccine Preventable Disease Program. Measles Exposure. January 2015. Available from: https://www.state.nj.us/health/ cd/documents/topics/measles/measles_exposures_ guidance_01_2015.pdf. Accessed 20 Jul 2018.

47. Orenstein WA, Hinman A, Nkowane B, Olivé JM, Reingold A. Measles and rubella global strategic plan 2012-2020 midterm review. Vaccine 2018;36(Suppl 1):A1-34. 